\title{
PASSENGER ROAD TRANSPORT TRENDS IN THE SLOVAK REPUBLIC
}

The article deals with the present trends in the passenger road transport in the Slovak Republic. It provides the characteristic of indicators of development phases of the passenger road transport trends. Existing increase of number of vehicles and individual road transport performances shall bring unfavourable impacts on environment on the one hand and on the other hand, it shall be the source of the state budget income.

Permanent conflict between individual road transport and mass passenger transport makes all administrative authorities to follow impacts on the life of inhabitants in agglomerations with assumed higher concentration of inhabitants. Demand for passenger cars will be permanent and any decrease in the passenger road transport cannot be assumed. Therefore, it is necessary to show a permanent interest in this sphere of problems and deal with it on the highest possible level.

\section{Introduction}

Following the Slovak Republic accession to the European structures and gradual market economy development, markedly changes have been accomplished including different social and population impacts.

At present, passenger road transport trends in our country are necessary to be studied in light of different aspects. On the one hand, existing increase of number of vehicles and individual road transport performances brings unfavourable impacts on environment and on the other hand it represents an income to the state budget from sale of fuels, vehicles and other items related to the passenger road transport.

A separate chapter includes building necessary transport areas, namely parking and lay-by areas, final building and maintaining good conditions of all road categories.

Most intensive passenger road transport development is evident in areas with high density of population where it causes difficulties in sustainable environment, i.e. it acts mainly as an unfavourable factor.

Permanent conflict between individual road transport and mass passenger transport makes all administrative bodies to follow impacts on the life of population in agglomerations with assumed higher concentration of inhabitants. It is necessary to determine an effective co-operation rate between individual road transport and mass passenger transport which is impossible in number of cases. Different measures, however, may be taken to influence effi- ciently modal split, particularly in the event of travels for work purposes, i. e. regularly repeated trips per day.

All present impacts on passenger road transport development which included, for example, the energy crisis at the beginning of seventies, the increase of fuel prices or cars didn't cause any markedly deceleration of development of the said mode of passenger transport. This trend may be observed not only in the developed countries where the degree of passenger road transport amounts to around 2.5 inhabitants per one passenger car but also in less developed countries with the degree of passenger road transport amounting to around 5.5 inhabitants per one passenger car.

\section{Present passenger road transport trends in Slovakia}

Issues concerning development and reach of reasonable saturation of individual transport needs of the population rank among topical issues, in particular, in relation to a living standard, the way of living and environment. Relation to a passenger car and to the passenger road transport trends in general represents an important factor. Opinions concerning passenger car have been different and reflect political and economic situation of the society.

Slovakia during its independence period has failed to reach the degree of passenger road transport of majority of European countries and it even lacks behind the Visegrad Four Countries or some Baltic Countries. At present, the degree of passenger road transport in Slovakia has amounted to about 4 inhabitants per one passenger car which in the Czech Republic has amounted to 2.4 inhabitants, in Hungary to 3.5 and in Poland to 3.1 inhabitants per one passenger car [2].

\footnotetext{
* Peter Faith

Department of Road Transport, Faculty of Operation and Economic of Transport and Communications, University of Zilina, Slovakia E-mail: Peter.Faith@fpedas.uniza.sk
} 
Resulting from experience the degree of passenger road transport of about 5 inhabitants per one passenger car starts to cause first problems within the society, which means the road safety, parking problems, etc. With the degree of passenger road transport of 2.5 inhabitants per one passenger car very serious problems occur in the urban traffic and the weekend peak hour traffic when car congestions are formed at entries to bigger towns.

Present passenger road transport trends in Slovakia may be characterised as gradually developing (Table 1). During the period from 1970 to 1980 number of passenger cars increased 3.4 times, from 1980 to 19901.6 times, from 1990 to 20001.5 times. Even though the comparison of present individual passenger road transport trends indicates that certain car boom level already has occurred in Slovakia it may be expected that a cyclic development with different level of increases will continue in the future.

Vehicle Number Trends in Slovakia

Table 1

\begin{tabular}{|c|c|c|c|}
\hline YEAR & Passengercars & $\begin{array}{c}\text { Passenger road } \\
\text { transport degree } \\
\text { /inhabitans/car/ }\end{array}$ & $\begin{array}{c}\text { Number } \\
\text { of passenger } \\
\text { cars/1000 } \\
\text { inhabit. }\end{array}$ \\
\hline 1965 & 53870 & 81.53 & 12.27 \\
\hline 1970 & 158690 & 28.61 & 34.95 \\
\hline 1975 & 339427 & 14.03 & 71.25 \\
\hline 1980 & 535952 & 9.32 & 107.27 \\
\hline 1985 & 687067 & 7.54 & 135.81 \\
\hline 1990 & 875550 & 6.07 & 165.95 \\
\hline 1995 & 1015794 & 5.28 & 189.24 \\
\hline 2000 & 1274244 & 4.24 & 235.86 \\
\hline 2005 & 1304705 & 4.13 & 242.10 \\
\hline 2006 & 1333749 & 4.04 & 247.28 \\
\hline
\end{tabular}

Source: The SR Presidency of the Traffic Police

Passenger road transport trends should be understood from two views; an external - social and an internal - an individual (a family). There is a narrow connection between exogenous and endogenous factors of the economic development. To carry out an exhausting analysis of this economic changes and decisions interaction means a very demanding task. In specification of individual passenger road transport development trends it is therefore necessary to result from existing experience and knowledge of countries which already have faced the similar problem. An assumed individual car transport development in Slovakia is presented in the alternative development scenarios by 2030 .

With regard to the Slovak economy orientation to the market economy an issue concerning the social establishment differences is insignificant and purely economic issues and issues concerning the way of living are foreground.

In connection with this it is necessary to mention the basic fact that Slovakia will be one of the countries with the highest portion of manufactured passenger cars per one inhabitant per year in the world.

This fact should also be taken in consideration in approach to the economic evaluation of individual road transport development which can be divided into several phases [1]:

- In Phase 1, leading economists considered the road transport trends together with building own manufacturing basis one of the main important factors which should speed-up economic development in the country; this period falls into the post-war economic restoration period. Phase 1 also covers the present period when after gaining an economic independence the passenger car manufacture development in Slovakia assumed a new dimension when two world automobile factories have added up the existing automobile factory;

- In Phase 2, a passenger car has been understood a mean of transport evaluated under commonly used criteria in evaluation of other public transport systems, i. e. an economic efficiency criterion of the basic mean in the light of transport sector;

- In Phase 3, an economic efficiency criterion has been transferred to the population personal consumption where a passenger car is understood a long-term consumed asset suitable for realisation of an increasing income of the population; its transportation function is secondary in number of cases;

- Finally, at present, the convergence of aspects all preceding development phases have occurred and a passenger car is on the one hand considered a mean of production for a group of people and on the other hand, a mean of transport satisfying best criteria for passenger transport.

In every development phase it is possible to accept an economic evaluation method where the amount of a gross national product (GNP) plays an important role from the social aspect. Time price depending on an income amount is decisive in the light of an individual, i.e., time saving expressed in monetary units achieved thanks to a passenger car use. The fact that the GNP amount depends to a certain level on number of passenger cars per inhabitant has already been proved in the preceding development phase analyses.

Upon gross national product increase per inhabitant in the country the number of passenger cars has increased while the time factor plays an important role and decrease of necessary GNP level per one car occurs with time in the country. It means that countries with lower GNP level are able to allocate a lower amount to passenger road transport than more developed countries with a higher GNP level. Foreign experience indicates that passenger road transport grows faster in the countries in which a higher GNP inter-year increase has been recorded than in the countries which reach a high GNP level/inhabitant in the long term and approach the saturation level of number of passenger cars per number of inhabitants. To compare the situation in the CR and Slovakia in 2005, there was 1000 EUR GNP/inhabitant sufficient for approximately 44 passenger cars/1000 inhabitants in the CR and this value corresponds to 35 passenger cars/1000 inhabitants in Slovakia. Yet more interesting is a comparison between some EU countries for 2002 presented in the following Fig. 1 [2]. 
Despite an unsteady SR economic development when the GNP development has recorded a higher level in comparison with other European countries it is possible to assume that the next individual passenger road transport development will be very dynamic. The preceding economic situation was rather complicated and non- transparent to forecast the passenger road transport trends and it was impossible to consider it sustainable and make definite conclusions. We may assume that the present economic growth will further continue in the next years thus increasing the rate of passenger cars/inhabitants in passenger road transport development.

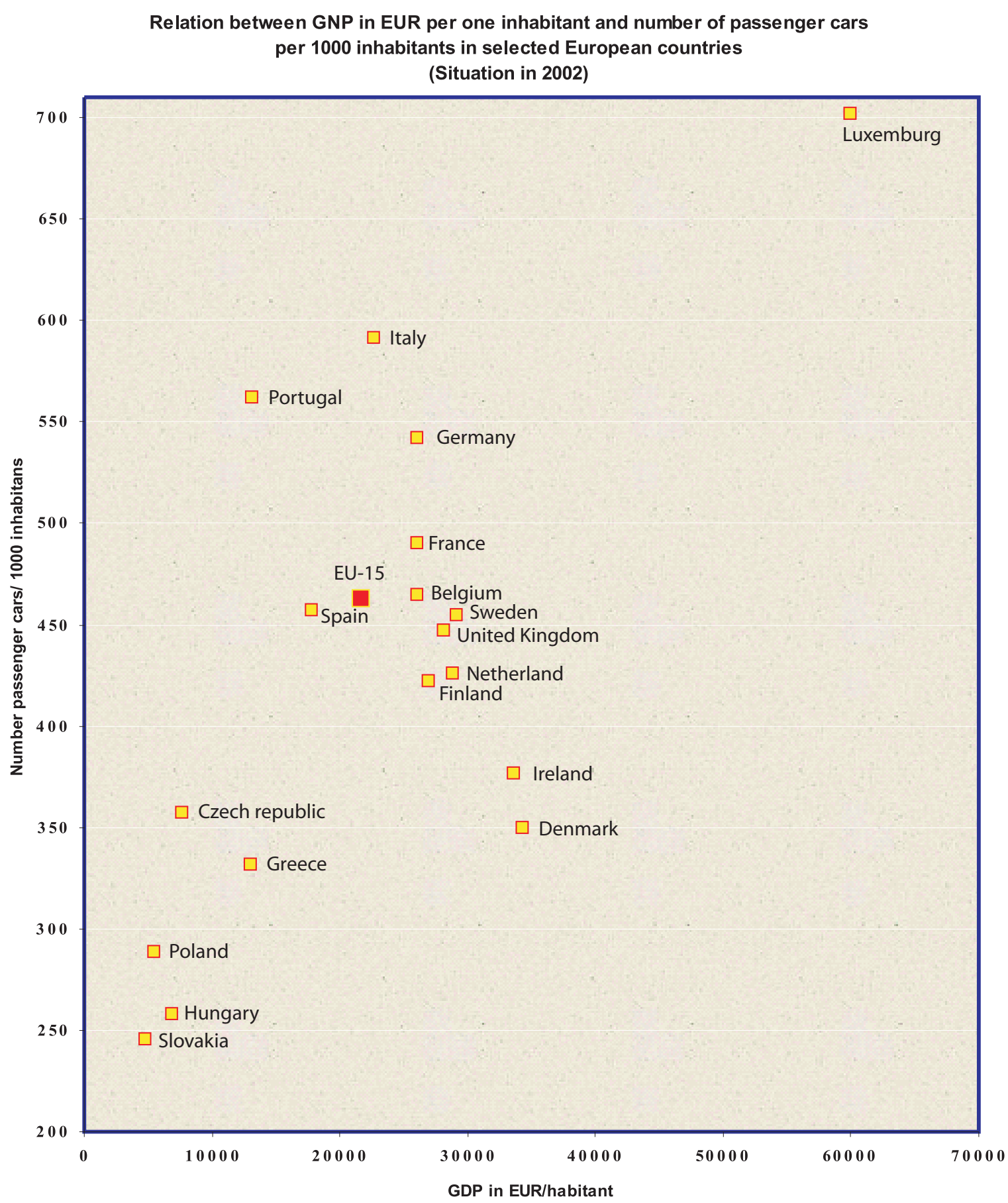

Fig. 1 Relation between GNP in EUR per one inhabitant and number of passenger cars per 1000 inhabitants in selected European countries 
Upon this strengthening of pretensions to a passenger car Slovakia will be able to reach soon some European countries.

From economic factors studies it is possible to derive both exogenous and endogenous factor impact on the passenger road transport development. Endogenous factors include a family income,

an average wage amount, a time price, and a way of living. The living standard which may be considered a summary explication of endogenous factors has been considerably differentiated.

A principal insufficiency rests upon the fact that differentiation has failed to proceed in accordance with the rate of labour and business results. The living standard has increased only with some preferred professions, while the living standard of majority of the population has considerably decreased. The aforesaid facts have influenced the level of passenger cars in Slovakia.

There are still more frequent "expensive" foreign cars on our roads on the one hand and on the other hand families with low income try to maintain in operation older cars which frequently do not comply with requirements for vehicle technical conditions.

Resulting from this economic analysis in the light of the high - optimistic scenario it is possible to expect the amount of 420 passenger cars per 1000 inhabitants, i.e. 1.4 inhabitants per 1 passenger car in 2030 [1].

\section{Passenger Road Transport Trends}

In the past, passenger road transport trends in Slovakia were characterised by different rates of growth of number of passenger cars [3]:

- 1965 - 1970 in average by $66.7 \%$,

- 1971 - 1975 in average by $43.0 \%$,

- 1976 - 1980 in average by $28.4 \%$,

- 1981 - 1985 in average by $17.5 \%$,

- 1986 - 1990 in average by $16.2 \%$

- 1991 - 1995 in average by $10.8 \%$,

- 1996 - 2000 in average by $13.3 \%$,

- 2001 - 2005 in average by $13.5 \%$

As in December 31, 2006 the total number of passenger cars in operation reached 1333305 units and the total number of motor vehicles reached 1710645 units [3].

In the light of the attained passenger road transport degree of 4.05 inhabitants per 1 passenger car, i.e. 247.28 passenger cars per 1000 inhabitants, Slovakia ranks among the European countries with the lowest passenger road transport development degree.

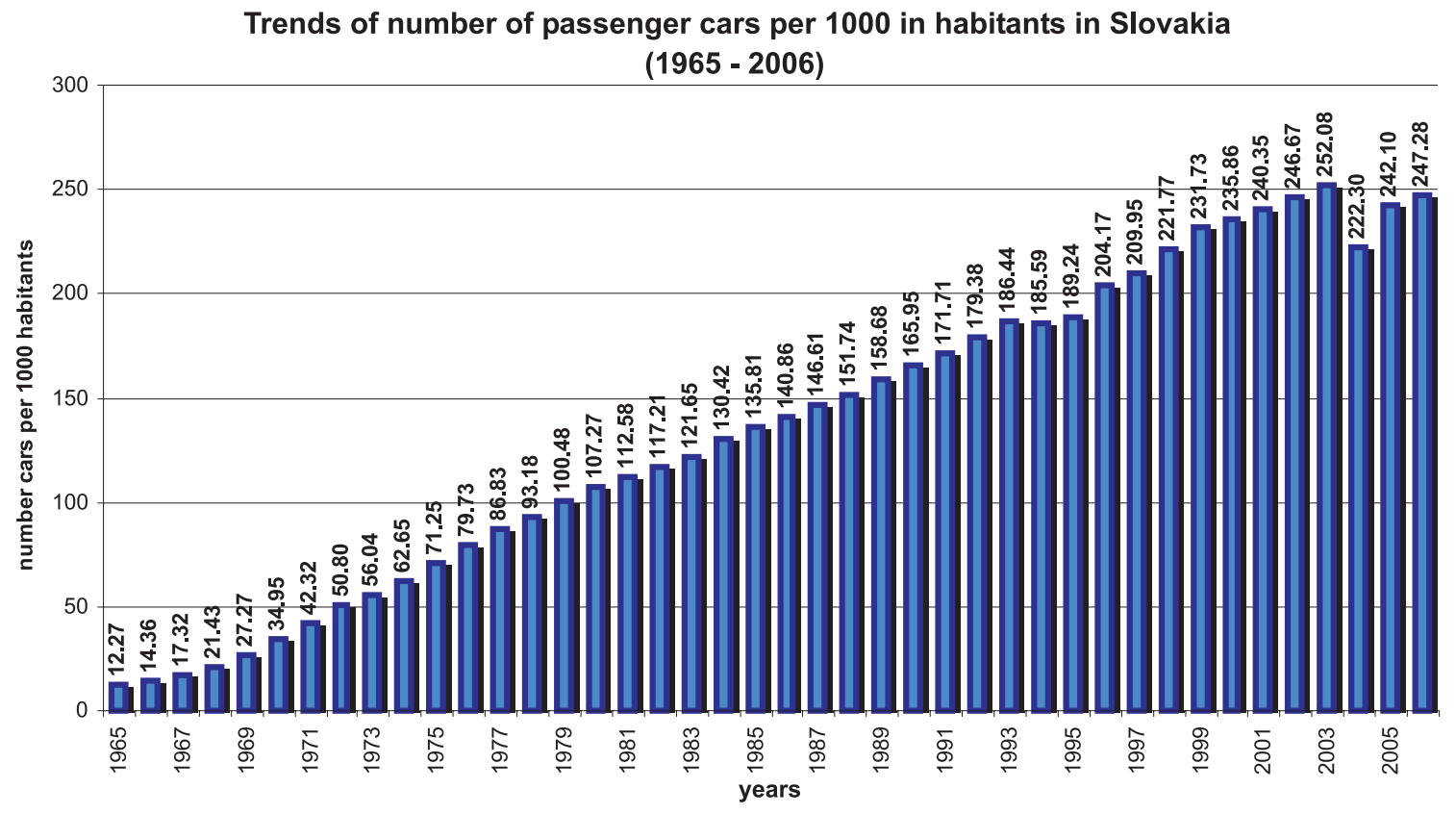

Source: The SR Presidency of the Traffic Police

Fig. 2 Trends of number of passenger car per 1000 inhabitants in Slovakia (1965-2006) 
The degree of passenger road transport development in Slovakia, however, did not develop equally in all areas of the country which was caused by number of reasons being not studied thoroughly yet.

As regards the passenger car degree, some regions as the Trencin region, the Presov and the Zilina regions reach only half of the Bratislava level. It is impossible to determine exactly causes of differences in the passenger car degree in individual SR regions. A survey and a more detail analysis should be performed. From the given Fig. 3 higher passenger car degree per inhabitants is shown in the Bratislava region, which is caused by a high degree of cars in the town where it attains 429.97 passenger cars per 1000 inhabitants [1].

Differences of passenger car degree per inhabitants according to individual regions (year 2006)

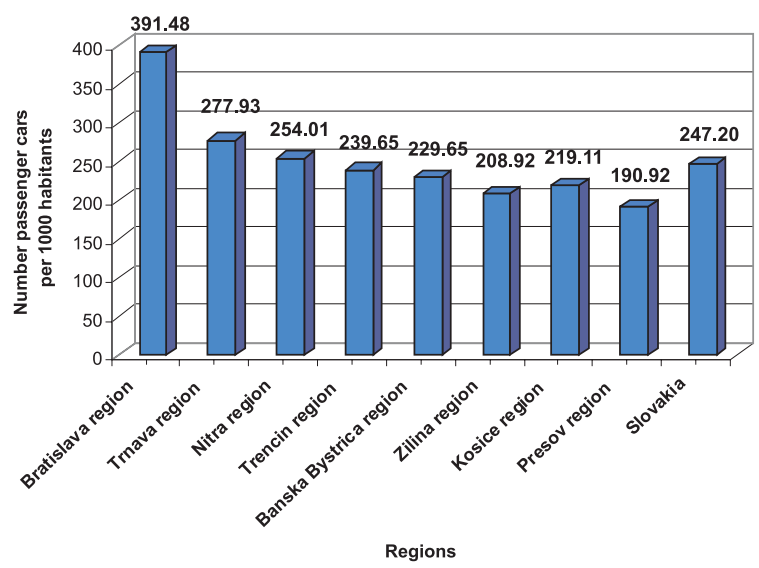

Source: The SR Presidency of the Traffic Police

Fig. 3 Differences of passenger car degree per inhabitants according to individual regions (year 2006)

\section{Passenger car sales and increases}

Trends of the specific passenger car increase registered by the transport police in Slovakia have been favourable. An annual average increase has represented 35000 units of passenger cars by now. It is interesting to compare an increase of number of inhabitants with number of passenger car increase for the analysed period from 1966 to 2006. When the proportion of number of inhabitants increase to the number of passenger car increase was more than 1 by 1985 , there was a turnover after 1985 when an annual increase of number of passenger cars exceeded the number of inhabitants increase (Fig. 4) [5, 4].

After 1989 principal changes occurred in the passenger car market. The supply - demand ratio turned after 1989 and all the world car makes have been gradually introduced in our market. At

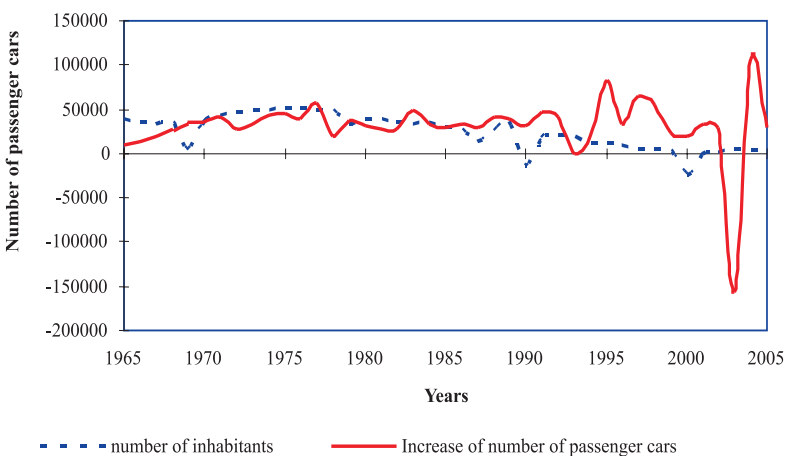

Source: The SR Presidency of the Traffic Police

Fig. 4 Trends in increase of number of passenger cars and inhabitants

present, there are 48 passenger car makes of different types and models marketed in our market.

Older cars which were either bought in the used-car dealerships and from sellers or imported from abroad should be also calculated in the passenger car increase.

Annually, there are 57000 new cars sold in average at our market. However, there were 74903 cars sold in total at our market in 1996 which was caused by cancellation of import duty on passenger cars with cylinder capacity by $1400 \mathrm{~cm}^{3}$.

In 2004 an obligatory replacement of car registration plates was introduced which caused higher number of older cars being removed from the Transport Inspectorate Records and significant decrease occurred in the real increase of passenger cars.

\section{Passenger car sales by car makes}

An annual passenger car increase (the difference between the newly registered cars and those removed from the Transport Inspectorate Records) represents around 40000 units.

For the period from 1965 to 2006 the first position was constantly held by Skoda car whose average annual sales represented approximately 15000 units, at present Fabia and Octavia types prevail. In recent years, Volkswagen, Renault, Peugeot, Opel and Citroen are other most frequently sold car makes. Certain shifts by car makes occurred at the passenger car market over the past two years. It can be said that the Slovak market is typically oriented at cheaper cars which must, however, meet basic usable properties, and its orientation is also aimed at car makes whose production started in Slovakia in 2006, i.e. Peugeot and Kia. While Peugeot belonged to the well sold cars also before 2006, Kia has attained very quickly an important position in the market; by 2006 number of sold Kia cars was low, some 500 units per year, after 2006 it 
attained the 6th position of the best sold cars and in 2007 it sold 3743 cars which means tripled sales of cars in 2006 [5].

\section{Passenger car lifetime}

An average passenger car lifetime may be assumed for $20-25$ years in the SR. More than 44000 passenger cars are older than 30 years. The highest number of passenger cars is within the range of 5 - 10 years of age which represents approximately 356000 units (Fig. 5) [3].

At present, an average age of the passenger car fleet is about 13 years. The above lifetime significantly exceeds values attained in the developed countries which results from two following factors:

- The relation between the total price of a new car and income of inhabitants;

- Amount of fuel price and spare part price for a passenger car.

Tax decrease of new vehicles and fuels and increase of spare part tax could lead to the decrease of an average lifetime to approx-

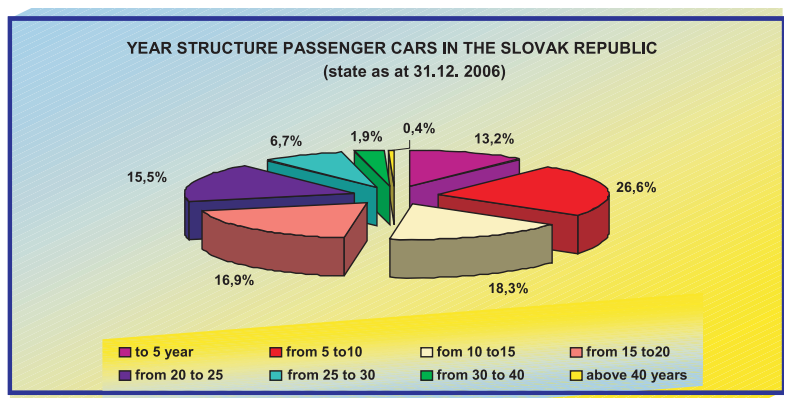

Source: The SR Presidency of the Traffic Police and own calculations Fig. 5 Year structure passenger cars in the Slovak Republic (state at 31.12.2006)

imately $15-18$ years and to the substantial increase of efficiency of operation of the entire passenger car fleet.

A long car life operation or its maintenance in the SR has been reflected in different fields, for example in:

- fuel consumption increase and their assortment preservation;

- necessity to produce, import and store spare parts for excessively/too long time (for 10 years),

- increase of material use for operation to ensure the operation fleet capabilities,

- deterioration of unfavourable impacts of the passenger road transport on environment etc.

\section{Conclusion}

Individual passenger road transport trends in the Slovak Republic will continue to move forward and in the light of the present experience it will be neither stopped by such events as energy crisis, increase of car and fuel prices in the past, nor by the measures taken in the tax or charge payments.

Macroeconomic indicators and the society sustainable development influence passenger road transport trends from external point of view and the way of living of inhabitants and their living standard influence it from an internal point of view. There is a narrow connection between exogenous and endogenous factors of the economic development. To perform an exhausting analysis of an interaction between the economic changes and decisions which influence passenger road transport is a very demanding task. In our conditions, this task is even more complicated for the present stage of the economic development and for the next stable development and line-up with more developed European countries.

The passenger road transport forecast should result from the present experience and knowledge of the countries attaining high degree of number of passenger cars per inhabitants.

It may be assumed that opinions concerning the passenger car ownership do not change, on the contrary, there is a permanent interest in a passenger car and its use will become an inevitable part of the everyday life of people for different purposes.

A passenger car meets a wide range of quality criteria laid on different purposes of trips. It is characterised by a high level of readiness for transport, high speed door-to-door transportation services, it is evaluated as a very comfortable means of transport and travelling by a passenger car ensures a maximum degree of privacy. In addition, many passenger car owners consider cars their hobby.

A passenger car compared with means of mass passenger transport still successfully competes in the high speed long distance transfer. A passenger car use gradually becomes a problem in urban areas with high density of population from both the environmental and time loss point of view where mass urban transport should take over a part of passengers, especially in trips for work purposes. From results of performed surveys resulted that a passenger car is used more frequently for trips to the work than means of mass passenger transport.

Assuming that the share of leisure time of inhabitants will increase it is possible to expect an increased interest in the passenger car use in trips for sport, recreational and holiday purposes.

From the point of view of the state the passenger road transport represents an effective source of income to the state budget into which flow important portions which partially return for the road infrastructure development. High quality and large capacity road infrastructure is inevitable to preserve the safe and continuous road traffic. Its level reflects the passenger road transport degree in the country

The passenger road transport from the social point of view should be also considered the factor stimulating activities in the region and creation of new work opportunities, the education level increase as well as the orientation in achieving new knowledge in modern technology. 
Modal split between the individual passenger transport and the public mass transport should be influenced by quality improvement of services provided mainly by urban mass transport. The individual passenger transport may reasonably substitute the public mass transport under certain conditions.

Finally, it should be mentioned that opinions concerning passenger road transport trend dynamics and its growth limits in our country may differ. However, in general, the number of passenger cars will no doubt increase in the next few decades.

\section{References}

[1] Research project: Development of the Individual Motoring in the Slovak Republic to 2020 (in Slovak), TRI Zilina, 1997

[2] http://epp.eurost.ec.europa.eu

[3] The Registration of Motor vehicles (in Slovak), The SR Presidency of the Traffic Police

[4] The Statistics Year Book (in Slovak), The Statistical Office of the Slovak Republic

[5] The Sale Survey of the Passenger Cars (in Slovak), The Automotive Industry Association of the Slovak Republic. 